\title{
Emerging Technologies of Polymeric Nanoparticles in Cancer Drug Delivery
}

\author{
Erik Brewer, Jason Coleman, and Anthony Lowman \\ Department of Chemical and Biological Engineering, Drexel University, 3141 Chestnut Street, Philadelphia, PA 19104, USA \\ Correspondence should be addressed to Erik Brewer, ecb34@drexel.edu
}

Received 2 June 2010; Accepted 2 August 2010

Academic Editor: Lu Sun

Copyright () 2011 Erik Brewer et al. This is an open access article distributed under the Creative Commons Attribution License, which permits unrestricted use, distribution, and reproduction in any medium, provided the original work is properly cited.

Polymeric nanomaterials have the potential to improve upon present chemotherapy delivery methods. They successfully reduce side effects while increasing dosage, increase residence time in the body, offer a sustained and tunable release, and have the ability to deliver multiple drugs in one carrier. However, traditional nanomaterial formulations have not produced highly therapeutic formulations to date due to their passive delivery methods and lack of rapid drug release at their intended site. In this paper, we have focused on a few "smart" technologies that further enhance the benefits of typical nanomaterials. Temperature and $\mathrm{pH}-$ responsive drug delivery devices were reviewed as methods for triggering release of encapsulating drugs, while aptamer and ligand conjugation were discussed as methods for targeted and intracellular delivery, with emphases on in vitro and in vivo works for each method.

\section{Introduction}

A major obstacle for chemotherapy is the inability to deliver adequate doses of drugs to the affected areas in the body. Systemic toxicity of these drugs limits their dose, while rapid clearance from circulation requires large doses in order to be effective. Doxorubicin, for instance, has a five to ten minute half life in the plasma [1].

Polymeric nanomaterials offer a promising solution by encapsulating chemotherapy drugs, and have been shown to reduce toxicity by providing a protective housing for the drug that limits its interaction with healthy cells [2-5]. As a result, the pharmacokinetic properties of the drug are based on the pharmacokinetic properties of the particle, as long as the drug can stay entrapped with the carrier until release is desired [6]. The potential benefits of such delivery devices also include controlled and long-term release rates, prolonged bioactivity, reduced side effects, increased patient compliance due to decreased administration frequency, and the ability to codeliver multiple drugs with synergistic effects to the same site [7-9].

Delivery devices made from erodible polymers are an attractive option over nonerodible ones because they degrade and gradually disappear after delivery [10]. Of these polymers, poly(e-caprolactone), poly(lactic acid) (PLA), poly(glycolic acid) (PGA), and their copolymers have been among the most extensively researched due to their biocompatibility, biodegradability, and regulatory approval [1115]. For an anticancer drug carrier to prove effective, prolonged circulation times and controlled drug release at the tumor site are required $[16,17]$. Various works have already been done to improve particle circulation time by limiting renal secretion and hindering uptake by the reticuloendothelial system (RES) [18-22]. This is often accomplished by pairing poly(ethylene glycol) (PEG) with the polymer of the nanoparticle. PEG has been shown to inhibit the binding of plasma proteins to the surface of polymeric drug carriers, preventing their recognition by the RES. This imparts "stealth" properties to the delivery device, increasing its systemic circulation time significantly [23].

Passive targeting is created because the size of the polymeric systems and their increased residence time make them suitable carriers to take advantage of the enhanced permeability and retention (EPR) effect in tumors $[6,24$, $25]$. The EPR effect is described as hyperpermeable tumor vessels that allow for the extravasation of circulating macromolecules, such as polymeric nanomaterials, that, combined with the lack of a lymphatic drainage system, results in their 
gradual accumulation [26]. While this results in localized delivery gradually over time, there still remains the need for drugs that act intracellularly to release and permeate the cell walls. In addition, it has been shown that slow and passive drug release from drug-carrying particles reduces their effectiveness in cancer treatment [27]. Overall, passive polymer drug carriers have not demonstrated increased therapeutic efficacy due to lack of intercellular and localized, rapid drug delivery [28-30].

Current research has thus focused on advancing these polymer vehicles with "smart" technologies that are responsive to environmental stimuli. These can be separated into two categories: (1) site-targeting, where particles actively search for and attach themselves to specific and diseased cells by the use of molecules such as ligands, antibodies, and aptamers; (2) site-triggering, where chemical or physical changes in the environment trigger the rapid release of the drug payload. This review focuses on a few selected "smart" technologies in each category: ligand and aptamer site-targeting particles, and $\mathrm{pH}$ and temperature-responsive particles.

\section{Smart Nanomaterials}

\subsection{Site-Targeted Nanomaterials}

2.1.1. Ligands. Attaching targeting ligands to the particle surface can take advantage of the overexpression of various receptors on tumor cell surfaces [31, 32]. Coupled with the passive accumulation at tumor sights caused by the EPR effect, targeted particles can increase the interaction time between particles and the tumor cell and increase the likelihood of the particles being taken up by the tumor cells via endocytosis [33].

Targeted delivery takes advantage of differences in the expression of cell surface receptors between healthy and tumor cells. For example, folate receptors are known to be vastly overexpressed in several human tumors [34-36]. Attaching folate to the outer shell of particles can create a targeted drug delivery carrier. Folate conjugation has shown success at creating targeted anticancer agents that can avoid nonspecific attacks on normal tissue and increase cellular uptake within target cells [31-33, 37, 38].

PEG is commonly associated with the surfaces of micellelike particles and liposomes to increase particle circulation. By coupling ligands to polyethylene glycol (PEG), a targeted particle can be created where the ligand is expressed on the particle surface. Combining the benefits of prolonged particle circulation with the benefits of delaying drug release, an ideal system exists for targeted delivery [33, 39-45]. The increased residence time increases the likelihood of interaction between receptor and target for targeted delivery.

Yoo et al. developed folate-conjugated PEG-co-poly (lactic-co-glycolic acid) (PEG-PLGA) micelles loaded with the anti-cancer drug doxorubicin that expressed folate on the micelle surface [33]. Studies indicated increased cytotoxicity and decreased tumor growth for folate conjugated micelles as opposed to nontargeted micelles and free DOX [33]. Targeted particles also showed increased cellular uptake [33].
2.1.2. Aptamers. Aptamers are DNA and RNA sequences that recognize specific target analytes [46]. Aptamers can be selected to bind with high specificity and affinity to a wide range of molecules such as organic dyes, amino acids, biological cofactors, antibiotics, peptides, proteins, and whole cells [47]. Aptamers are often compared to antibodies for their affinity to select molecules, but despite their similarities, offer several important advantages: aptamers can be easily synthesized in vitro without the need for an induced immune response from animals [48], which makes them able to target nonimmunogenic molecules; the aptamer synthesis process, SELEX, can be carried out in nonphysiological settings [49]; they are more stable and can be obtained at a lower cost [50].

Since the targeted molecule can be uniquely associated with a particular disease, early research into aptamers has concentrated on early-stage disease diagnosis, particularly in cancer. Common cancer diagnostic methods involve somatic or visual techniques, such as self-examinations and localized $\mathrm{X}$-rays. A major disadvantage of these methods is that they do not lead to diagnoses until advanced stages in the disease, a factor in cancers high death rates $[51,52]$. However, cancer is a genetic disease, and aptamers provide a way for screening at the molecular level using selective cell binding [53].

Cancer-detecting assays using fluorescent imaging that are currently being developed utilize aptamers conjugated with dye-doped silica nanoparticles. These fluorescent nanoparticles are favored over direct dye conjugation due to their signal amplification and ability to immobilize biomolecules [54-56]. These particles have often combined with magnetic particles, which allows for convenient separation of bound cells, to make two-part aptamer-based assays $[53,57,58]$. Gold nanoparticles, which are ideal contrasting agents, have been conjugated with cancer-targeting aptamers to successfully create assays for detecting prostate and breast cancer cells $[59,60]$.

The ability of aptamers to bind directly with diseased cells has gained them recognition in site-specific drug delivery research. In particular, systems utilizing polymeric nanovehicle and aptamer conjugates are believed to create devices that can deliver high drug doses to diseased cells in a controlled fashion with minimal toxicity to healthy cells.

In vitro studies involving these systems often utilize the A10 2'-fluoropyrimidine RNA aptamer, which targets the prostate-specific membrane antigen (PSMA) found on the LNCaP cell line. This allows for comparison with control groups tested against PC3 cells, another prostatecancer cell line that does not display the PSMA antigen, to prove that the drug carriers only have affinity for cells expressing the targeted antigen [61-63]. Using fluorescent imaging, this comparison was able to establish that drug vehicles conjugated with the PSMA-targeting aptamer were internalized by cells via receptor-mediated endocytosis [64]. PEG-PLGA nanoparticles carrying the chemotherapy drug docetaxel and targeting PSMA cells in vivo have produced dramatic reduction in tumor sizes in mice compared to free docetaxel and non-targeted particles [61]. The increase in cancer cell toxicity was credited to a combination of the intracellular delivery of the drug, increased retention time, 
and reduced circulation clearance at the tumor site due to high-affinity binding with the antigen.

Polymeric micelles have proven to increase the overall affinity of aptamers that exhibit ones considered too low for drug-aptamer delivery systems [65]. They do this by taking advantage of multivalent binding effects, where multiple aptamers on the micelle surface link with the cell-surface antigens to produce an overall stronger bond. This allows for the targeting of unique cellular antigens that would otherwise be considered unsuitable for drug-aptamer conjugates.

Polymeric nanocarriers provide the benefit of being able to carry multiple drugs in the same vehicle. This, combined with aptamer targeting, can be used to selectively deliver dual-drug payloads to cancerous cells. Due to their different mechanisms of action, the drugs may provide additive or synergistic effects that can allow for lower doses, and reduce side effects $[66,67]$. More importantly, this is thought to combat drug resistance, a major problem associated with cancer drug treatment [68]. Packaging the drugs in a nanocarrier, as opposed to a simple mixture, allows for their simultaneous delivery on a cell-by-cell basis, which has been proven to be more effective [69-71].

This can even be used to combine drugs with different water solubility properties, as was accomplished by Zhang et al. using PEG-PLGA [9]. In systems where the aptamer binding initiates endocytosis, such as with A10 RNA aptamer, combinations of drugs and genes that require delivery to intracellular compartments to properly function experience greater benefits [72]. This approach has been used successfully in aptamer-gene conjugates $[73,74]$, and is beginning to see promise in aptamer-nanoparticle conjugates. Polyethyleneimine-grafted-PEG (PEI-PEG) nanoparticles carrying doxorubicin and the hairpin shRNA, which suppresses the antiapoptotic gene $\mathrm{Bcl}$-xl, produced significantly lower cell viability and enhanced therapeutic efficacy compared to single drug-loaded nanoparticle aptamer systems and free drug mixtures [75].

\subsection{Site-triggered Nanomaterials}

2.2.1. pH-Responsive Nanomaterials. One method to promote drug release at the tumor sight is by taking advantage of the lower $\mathrm{pH}$ of the tumor's microenvironment. Mildly acidic conditions exist in tumor and inflammatory tissues $(\mathrm{pH}$ 6.8) and in endosomes $(\mathrm{pH}$ 5-6) in comparison to the more neutral physiological condition $(\mathrm{pH} 7.4)$ [76, 77]. The ability of nanoparticles to accumulate in solid tumors has been shown by the enhanced permeation and retention (EPR) effect $[6,24,25,78]$. In addition, it has also been demonstrated that nanoparticles can be taken up within cancer cells through a process called endocytosis $[79,80]$. Many anticancer drugs, such as doxorubicin, work by inhibiting cell replication. Thus, for anticancer drugs to be effective, they must interact with intracellular components. If particles can gain access to the intracellular components through endocytosis, then it seems logical that the particle deliver its payload of anticancer drugs once inside the cell. Once the particle is taken up via endocytosis, the endocytic vesicles ultimately change to late endosomes and then to lysosomes in which the proton concentration is 100 times higher ( $\mathrm{pH}$ 5.0) than the physiological condition ( $\mathrm{pH} 7.4$ ) [76]. Micelle forming polymer-drug conjugates and drug loaded liposomes provide the potential for drug release within a lower $\mathrm{pH}$ environment. Drug release from micelles can be targeted to these acidic environments by conjugating the polymer to the drug with an acid-cleavable linkage. Release can be targeted to acidic conditions in liposomes by causing destabilization of the liposome shell under acidic conditions.

Nanomaterials such as liposomes and micelles are examples of particles that can accumulate in solid tumors as a result of the EPR effect [3, 9-11]. Micelles consist of a hydrophobic core and a hydrophilic corona or shell and are well suited to entrap and solubilize hydrophobic drugs within their core. Because some of the most commonly used cancer drugs are hydrophobic, micelles have gained widespread use for the delivery of cancer therapeutics [39, $41,42,45,80-83]$. Liposomes typically involve a bimolecular phospholipid membrane that encloses an aqueous compartment. Because liposomes contain a phospholipid membrane they can entrap hydrophobic drugs, but they can also encapsulate various hydrophilic drugs such as peptides, proteins, and nucleic acids within their aqueous compartment $[84,85]$. Previous work has been done to increase liposome stability by increasing circulation time and by preventing drug leakage until the target is reached [8688]. Micelle like particles and liposomes with $\mathrm{pH}$ sensitivity have shown great promise as delivery vehicles for anticancer drugs, DNA, RNA, proteins, and peptides [76, 82, 89-98].

In order for micelles to take on $\mathrm{pH}$ responsibilities, the drug is typically conjugated to the polymer that makes up the core of the micelle by an acid cleavable linkage. The creation of a polymer-drug conjugation is referred to as a polymeric prodrug and allows the drug to remain inactive until cleavage from the polymer carrier. When used in the formation of micelles, polymeric prodrugs can control release by chemically attaching the drug within the core of the micelle or by increasing the thermodynamic stability of the micelle in order to delay micelle degradation $[39,99]$. In order to prolong drug release, an active substance can be linked to a polymeric molecule via a covalent bond which is naturally hydrolyzed in vivo [100-102]. For $\mathrm{pH}-$ responsiveness of polymeric prodrug micelles, the linkage between drug and polymer is more readily hydrolyzed at a lower $\mathrm{pH}$.

If taken up via endocytosis, drug association with a polymer carrier can help avoid the multidrug resistance (MDR) effect (i.e. recycling of chemotherapy drugs). Drug association with a polymer carrier, either through conjugation or entrapment within the micelle core, can help limit free drug being outfluxed from the cancer cell through the p-glycoprotein pump.

Various works have been done involving the conjugation of the anti-cancer drug doxorubicin (DOX) to the hydrophobic core forming polymer of the micelle [82, 89, 93, 94]. The conjugation of drug to polymer was performed via a hydrazone linkage and ultimately resulted in enhanced DOX accumulation and cytotoxicity within tumor cells as opposed 
to free DOX. One of the more promising aspects for this type of $\mathrm{pH}$-responsive release is the ability of the DOX-conjugated micelles to circumvent the multi-drug resistant effect once taken up by endocytosis [82].

One of the main disadvantages of conjugating the drug to the polymer to get $\mathrm{pH}$ responsiveness is the need to maintain drug bioactivity throughout the conjugation scheme. Liposomes that are $\mathrm{pH}$ responsive overcome this barrier because the shell of the liposomes is what can be tailored to exhibit $\mathrm{pH}$ effects. Because of previous work to increase liposome stability and circulation, the liposome can circulate long enough to passively reach the target sight (EPR effect), and the drug can stay associated with the liposome until the proper $\mathrm{pH}$ environment is reached $[85-88,91]$.

In order for liposomes to deliver their payload at the intracellular layer, the liposomes must first be taken up by endocytosis. Once taken up, the liposomes need to destabilize at the lower endosomal $\mathrm{pH}$. This destabilization can allow the liposome to break down and deliver its contents into the cell cytoplasm. Modification by the inclusion of lipids with $\mathrm{pH}$ sensitivity can give the liposome "fusogenic" properties[91]. The term fusogenic refers to the ability of liposomes to destabilize at the lower endosomal $\mathrm{pH}$ and "fuse" with the endosomal bilayer to allow for access to the cell cytoplasm. This first became a desired intracellular release mechanism by the observation that certain viruses take advantage of the endosomal acidification to infect cells[91]. Acidic environments within the body also occur at tumors, inflamed or infected tissue, where $\mathrm{pH}$ sensitive delivery may also be desirable.

The most common $\mathrm{pH}$-sensitive liposomes are composed of phosphatidylethanolamine (PE) as the primary bilayer component combined with compounds that are stable at a neutral pH, but unstable under acidic conditions [91]. Altering $\mathrm{pH}$ sensitivity is typically done by including $\mathrm{pH}$-sensitive lipids, synthetic peptides/proteins, or $\mathrm{pH}$-sensitive polymers within the lipid bilayer or the liposome aqueous compartment [91, 103-108]. With PE liposomes destabilization occurs by intercalation of amphiphilic molecules that contain a protonatable acidic group (i.e. a carboxylic group) that becomes protonated under acidic conditions and causes the PE molecule to revert to an inverted and unstable hexagonal phase [91, 109, 110]. Some of the most effective molecules included within the bilayer that induce $\mathrm{pH}$ sensitivity and ultimately, increase drug delivery to the cytoplasm, consist of combinations of dioleoylphosphatidylethanolamine (DOPE) and cholesteryl hemisuccinate (CHEMs) $[91,111,112]$.

2.2.2. Thermoresponsive. Hyperthermia has been investigated as a method for triggered drug release to targeted areas in thermoresponsive liposomes. Here, in vivo temperatures are achieved through either older and more general methods, such as warmed baths or perfusates [113], or through more advances and localized methods, requiring ultrasonic and microwave units $[114,115]$. Since most mammalian cells begin to show damage at $42^{\circ} \mathrm{C}[116]$, hyperthermia is defined as temperatures between this and physiological temperature $\left(37^{\circ} \mathrm{C}\right)$. When the liposomes pass through the area with increased temperature, they release their encapsulated drugs.
In addition to localized drug release, hyperthermia offers other indirect benefits, such as increased microvessel permeability in tumors, which causes more liposomes to accumulate at the intended site $[117,118]$ while healthy microvessels are not significantly altered [119]; increased cell permeability, which allows the released drugs to diffuse through the cell walls more easily [120]; and increased sensitivity to thermal injury compared to healthy cells [121].

To take advantage of this triggering mechanism, liposomes must have a liquid-crystalline transition temperature $\left(T_{c}\right)$ within the accepted temperature range. Upon reaching this temperature, they become highly permeable to their water-soluble contents, causing hydrophilic drugs to release in the intended location $[122,123] . T_{c}$ is a material property of the liposome polymer and is primarily determined by the length of its fatty acid chains [124]. This allows for the addition of other polymers to the liposome, notably polyethylene glycol (PEG), to increase the retention time and stability [125] and alter the release kinetics [126, 127], without significantly changing its transition temperature. To achieve a desirable $T_{c}$, it is possible to combine polymers with different transition temperatures in ratios that result in one in the hyperthermic range [128].

In order for a thermosensitive liposome to be considered for a drug-delivery device, it must be stable in plasma circulation, release minimal amount of drug at physiological temperatures, and then release its payload quickly in hyperthermia conditions. Common phospholipids include 1,2-dihexadecanoyl-sn-glycero-3-phosphocholine (DPPC), 1,2-distearoyl-sn-glycero-3-phosphocholine (DSPC), 1,2distearoyl-sn-glycero-3-phosphoethanolamine (DSPE), and 1,2-dipalmitoyl-sn-glycero-3-phosphoglyceroglycerol (DPPGOG), often in combination and with varying amounts of PEG [27, 113, 129-131].

In vivo experimentation has proven promising for these thermo-sensitive devices. The chemotherapy drug carboxyfluorescein (CF) produced a sixfold bioavailability increase in cancerous hamsters when packaged in a thermosensitive liposome under hyperthermia compared to free CF [131]. Similar nanovehicles carrying DOX successfully eliminated tumors in six out of nine cancerous mice after 60 days [132]. In a phase I clinical trial, temperature-sensitive liposomes carrying DOX were given to dogs with solid tumors in conjunction with localized hyperthermia. The study reported a 17 -fold decrease in drug clearance rate when using the liposomes compared to the free drug, resulting in a higher bioavailability [133].

Alternatively, copolymers have been designed that have a different thermo-sensitive property, called the cloud point (CP), which changes over time, eliminating the need for hyperthermic conditions. Above the $\mathrm{CP}$, the co-polymer precipitates out of solution and freely forms micelles that can encapsulate their drug; below the $\mathrm{CP}$, the polymer dissolves into solution, causing the micelle to destabilize and release its payload [134]. Thus, these co-polymers are designed to begin with a $\mathrm{CP}$ that is below ambient conditions so that a drug vehicle can be made, and then end with a CP that is above physiological temperature after the micelles have been delivered to the target cells [135]. 
This has been achieved through the use of a novel class of hydrophobic lactate-containing polymers, notably poly(N-(2-hydroxypropyl) methacrylamide oligolactates) (pHPMAm-Lac $\left.{ }_{n}\right)$ and poly $(N$-(2-hydroxyethyl) methacrylamide)-oligolactates (pHEMAm- $\mathrm{Lac}_{n}$ ). The change in CP over time is caused by the hydrolysis of the lactate side group: as the polymer degrades and the lactate hydrolyzes, the polymer becomes more hydrophilic, causing an increase in the CP [134]. In both polymers, the initial CP is dependent on the length of the lactate chain, and can thus be tailored, though pHPMAm-Lac 2 and pHEMAm$\mathrm{Lac}_{2}$ provide the most convenient $\mathrm{CPs}$ of $10^{\circ} \mathrm{C}$ [136] and $22^{\circ} \mathrm{C}$ [137], respectively. To create an amphiphilic block copolymer, PEG is most commonly used as the hydrophilic segment to take advantage of its stealth properties and longer circulation times [138], as previously described.

These micelles have encountered obstacles in preliminary in vitro and in vivo experimentation, as release kinetics of encapsulated paclitaxel have been in large part due to diffusion rather than micelle destabilization [139]. In addition, fast degradation kinetics of the lactate chains, causing quick micelle destabilization, resulted in no measurable accumulation in mice $24 \mathrm{~h}$ after i.v. injection [140]. However, mPEG- $b$-p (HEMAm-Lac ${ }_{n}$ ) polymers modified with methacryloxy-chloride in the micelle core have displayed prolonged circulation times in vivo and increased tumor accumulation compared to unmodified micelles [141]. This new class of thermosensitive polymers shows promise for future chemotherapy work.

2.3. Combined Smart Technologies. Because targeted particles can increase uptake by endocytosis, $\mathrm{pH}$-sensitive release is desirable. Combining the benefits of a receptor-targeted micelle and a $\mathrm{pH}$-responsive drug conjugate was performed by Bae et al. [92-95]. Targeting a surface receptor on cancer cells can cause increased cellular uptake, and a $\mathrm{pH}$-responsive degradable bond between drug and polymer can cause release in the low $\mathrm{pH}$ environment of the lysosome. Folate was used as the targeting molecule and the $\mathrm{pH}$-responsive hydrazone bond was used to conjugate DOX to the polymer. The self-assembling block copolymers required to prepare the targeted and $\mathrm{pH}$-responsive micelles (approximately 60 $\mathrm{nm}$ ), consisted of folate-PEG-poly(aspartate hydrazone doxorubicin) [FOL-PEG-P(Asp-Hyd-DOX)]. Delivery to tumor cells known to overexpress folate receptors has been shown with micelles using folate as the targeting moiety to cause increased endocytotic cellular uptake into the intracellular acidic compartments known as endosomes (pH 5-6) [33]. Drugs conjugated within a micelle by a hydrazone linkage show selective release within the low $\mathrm{pH}$ environment of endosomes $[76,82,89]$.

In terms of effective dose (ED), the effective doses for free DOX and micelles without folate were similar, but the ED for folate conjugated micelles was lowered 2-fold compared to the free DOX micelles [93]. The overall findings by Bae et al. suggest that an intracellular, environment-targeting micelle drug carrier is one of the most effective approaches for cancer treatment [92]. Liposomes with $\mathrm{pH}$-sensitivity and targeting ligands have also been effectively used to increase residence time at the target cells, increase uptake, and increase intracellular delivery $[37,96,98]$.

\section{Conclusion}

Smart technologies in polymer nanomaterials offer a unique way to deliver chemotherapy drugs to their intended target without affecting healthy cells. By utilizing the naturally low $\mathrm{pH}$ environment found in tumors and endosomes, these drug carriers are free to circulate in the body, only releasing their drugs at their intended location. Thermosensitive polymer vehicles, when combined with localized hyperthermia, can be triggered to release their payload at the desired site. Ligands and aptamers, on the other hand, provide a way for these vehicles to actively target cancerous cells and then induce receptor-mediated endocytosis for intracellular delivery. Compared to free drug and passive nanomaterial systems, these smart devices have proven to increase therapeutic effects and efficacy in a variety of cellular and animal models. Progression of these techniques will eventually lead to increased accuracy in delivering higher doses and more toxic drugs, which will require challenges like premature drug release and false cell targeting to be addressed. As these technologies are further developed and other methods of triggering and targeting emerge, smart polymer nanomaterials will be able to provide improved cancer treatment methods.

\section{References}

[1] P. K. Working and A. D. Dayan, "Pharmacologicaltoxicological Expert Report. Caelyx. (Stealth liposomal doxorubicin $\mathrm{HCl}$ )," Human and Experimental Toxicology, vol. 15, no. 9, pp. 751-785, 1996.

[2] T. L. ten Hagen, A. L. Seynhaeve, S. T. van Tiel, D. J. Ruiter, and A. M. Eggermont, "Pegylated liposomal tumor necrosis factor- $\alpha$ results in reduced toxicity and synergistic antitumor activity after systemic administration in combination with liposomal doxorubicin (Doxil) in soft tissue sarcoma-bearing rats," International Journal of Cancer, vol. 97, no. 1, pp. 115120, 2002.

[3] A. Gabizon, H. Shmeeda, and Y. Barenholz, "Pharmacokinetics of pegylated liposomal doxorubicin: review of animal and human studies," Clinical Pharmacokinetics, vol. 42, no. 5, pp. 419-436, 2003.

[4] A. A. Gabizon, "Selective tumor localization and improved therapeutic index of anthracyclines encapsulated in longcirculating liposomes," Cancer Research, vol. 52, no. 4, pp. 891-896, 1992.

[5] D. W. Northfelt, F. J. Martin, P. Working et al., "Doxorubicin encapsulated in liposomes containing surface-bound polyethylene glycol: pharmacokinetics, tumor localization, and safety in patients with AIDS-related Kaposi's sarcoma," Journal of Clinical Pharmacology, vol. 36, no. 1, pp. 55-63, 1996.

[6] T. M. Allen and P. R. Cullis, "Drug delivery systems: entering the mainstream," Science, vol. 303, no. 5665, pp. 1818-1822, 2004.

[7] M. Yokoyama, T. Okano, Y. Sakurai, H. Ekimoto, C. Shibazaki, and K. Kataoka, "Toxicity and antitumor activity 
against solid tumors of micelle-forming polymeric anticancer drug and its extremely long circulation in blood," Cancer Research, vol. 51, no. 12, pp. 3229-3236, 1991.

[8] M. L. Hans and A. M. Lowman, "Biodegradable nanoparticles for drug delivery and targeting," Current Opinion in Solid State and Materials Science, vol. 6, no. 4, pp. 319-327, 2002.

[9] L. Zhang, A. F. Radovic-Moreno, F. Alexis et al., "Co-delivery of hydrophobic and hydrophilic drugsfrom nanoparticleaptamer bioconjugates," ChemMedChem, vol. 2, no. 9, pp. 1268-1271, 2007.

[10] R. Herrero-Vanrell and M. F. Refojo, "Biodegradable microspheres for vitreoretinal drug delivery," Advanced Drug Delivery Reviews, vol. 52, no. 1, pp. 5-16, 2001.

[11] D. H. Lewis, "Controlled release of bioactive agents from lactide/glycolide polymers," in Biodegradable Polymers as Drug Delivery Devices, M. Chasin and R. Langer, Eds., pp. 141, Marcel Dekker, New York, NY, USA, 1990.

[12] R. Langer and J. P. Vacanti, “Tissue engineering," Science, vol. 260, no. 5110, pp. 920-926, 1993.

[13] E. Chiellini and R. Solaro, "Biodegradable polymeric materials," Advanced Materials, vol. 8, no. 4, pp. 305-313, 1996.

[14] B. Jeong, Y. H. Bae, D. S. Lee, and S. W. Kim, "Biodegradable block copolymers as injectable drug-delivery systems," Nature, vol. 388, no. 6645, pp. 860-862, 1997.

[15] K. Okada, H. Kawaide, T. Kuzuyama, H. Seto, I. S. Curtis, and Y. Kamiya, "Antisense and chemical suppression of the nonmevalonate pathway affects ent-kaurene biosynthesis in Arabidopsis," Planta, vol. 215, no. 2, pp. 339-344, 2002.

[16] A. Lavasanifar, J. Samuel, and G. S. Kwon, "Poly(ethylene oxide)-block-poly(L-amino acid) micelles for drug delivery," Advanced Drug Delivery Reviews, vol. 54, no. 2, pp. 169-190, 2002.

[17] M. Yokoyama, M. Miyauchi, N. Yamada et al., "Characterization and anticancer activity of the micelleforming polymeric anticancer drug Adriamycin-conjugated poly(ethylene glycol)-poly(aspartic acid) block copolymer," Cancer Research, vol. 50, no. 6, pp. 1693-1700, 1990.

[18] D. D. Lasic, J. J. Vallner, and P. K. Working, "Sterically stabilized liposomes in cancer therapy and gene delivery," Current Opinion in Molecular Therapeutics, vol. 1, no. 2, pp. 177-185, 1999.

[19] T. M. Allen, M. S. Newman, M. C. Woodle, E. Mayhew, and P. S. Uster, "Pharmacokinetics and anti-tumor activity of vincristine encapsulated in sterically stabilized liposomes," International Journal of Cancer, vol. 62, no. 2, pp. 199-204, 1995.

[20] R. Gref, M. Lück, P. Quellec et al., “'Stealth' corona-core nanoparticles surface modified by polyethylene glycol (PEG): influences of the corona (PEG chain length and surface density) and of the core composition on phagocytic uptake and plasma protein adsorption," Colloids and Surfaces B, vol. 18, no. 3-4, pp. 301-313, 2000.

[21] R. Gref, Y. Minamitake, M. T. Peracchia, V. Trubetskoy, V. Torchilin, and R. Langer, "Biodegradable long-circulating polymeric nanospheres," Science, vol. 263, no. 5153, pp. 1600-1603, 1994.

[22] M. Tobío, R. Gref, A. Sánchez, R. Langer, and M. J. Alonso, "Stealth PLA-PEG nanoparticles as protein carriers for nasal administration," Pharmaceutical Research, vol. 15, no. 2, pp. 270-275, 1998.

[23] D. E. Owens III and N. A. Peppas, "Opsonization, biodistribution, and pharmacokinetics of polymeric nanoparticles," International Journal of Pharmaceutics, vol. 307, no. 1, pp. 93$102,2006$.
[24] X. Zhang, Y. Li, X. Chen et al., "Synthesis and characterization of the paclitaxel/MPEG-PLA block copolymer conjugate," Biomaterials, vol. 26, no. 14, pp. 2121-2128, 2005.

[25] H. Maeda, J. Wu, T. Sawa, Y. Matsumura, and K. Hori, "Tumor vascular permeability and the EPR effect in macromolecular therapeutics: a review," Journal of Controlled Release, vol. 65, no. 1-2, pp. 271-284, 2000.

[26] R. Duncan, M. J. Vicent, F. Greco, and R. I. Nicholson, "Polymer-drug conjugates: towards a novel approach for the treatment of endrocine-related cancer," Endocrine-Related Cancer, vol. 12, supplement 1, pp. S189-S199, 2005.

[27] L. Li, T. L. M. ten Hagen, D. Schipper et al., "Triggered content release from optimized stealth thermosensitive liposomes using mild hyperthermia," Journal of Controlled Release, vol. 143, no. 2, pp. 274-279, 2010.

[28] P. J. Cagnoni, "Liposomal amphotericin B versus conventional amphotericin B in the empirical treatment of persistently febrile neutropenic patients," Journal of Antimicrobial Chemotherapy, vol. 49, supplement 1, pp. 81-86, 2002.

[29] I. Judson, J. A. Radford, M. Harris et al., "Randomised phase II trial of pegylated liposomal doxorubicin (DOXIL/CAELYX) versus doxorubicin in the treatment of advanced or metastatic soft tissue sarcoma: a study by the EORTC Soft Tissue and Bone Sarcoma Group," European Journal of Cancer, vol. 37, no. 7, pp. 870-877, 2001.

[30] T. J. Walsh, R. W. Finberg, C. Arndt et al., "Liposomal amphotericin b for empirical therapy in patients with persistent fever and neutropenia. National Institute of Allergy and Infectious Diseases Mycoses Study Group," New England Journal of Medicine, vol. 340, no. 10, pp. 764-771, 1999.

[31] J. Y. Lu, D. A. Lowe, M. D. Kennedy, and P. S. Low, "Folatetargeted enzyme prodrug cancer therapy utilizing penicillin$\mathrm{V}$ amidase and a doxorubicin prodrug," Journal of Drug Targeting, vol. 7, no. 1, pp. 43-53, 1999.

[32] Y. Lu and P. S. Low, "Folate targeting of haptens to cancer cell surfaces mediates immunotherapy of syngeneic murine tumors," Cancer Immunology, Immunotherapy, vol. 51, no. 3, pp. 153-162, 2002.

[33] H. S. Yoo and T. G. Park, "Folate receptor targeted biodegradable polymeric doxorubicin micelles," Journal of Controlled Release, vol. 96, no. 2, pp. 273-283, 2004.

[34] J. Cummings and C. S. McArdle, "Studies on the in vivo disposition of adriamycin in human tumours which exhibit different responses to the drug," British Journal of Cancer, vol. 53, no. 6, pp. 835-838, 1986.

[35] D. Goren, A. T. Horowitz, D. Tzemach, M. Tarshish, S. Zalipsky, and A. Gabizon, "Nuclear delivery of doxorubicin via folate-targeted liposomes with bypass of multidrugresistance efflux pump," Clinical Cancer Research, vol. 6, no. 5, pp. 1949-1957, 2000.

[36] S. D. Weitman, A. G. Weinberg, L. R. Coney, V. R. Zurawski, D. S. Jennings, and B. A. Kamen, "Cellular localization of the folate receptor: potential role in drug toxicity and folate homeostasis," Cancer Research, vol. 52, no. 23, pp. 67086711, 1992.

[37] J. A. Reddy and P. S. Low, "Enhanced folate receptor mediated gene therapy using a novel $\mathrm{pH}$-sensitive lipid formulation," Journal of Controlled Release, vol. 64, no. 1-3, pp. 27-37, 2000.

[38] S. Wang, R. J. Lee, G. Cauchon, D. G. Gorenstein, and P. S. Low, "Delivery of antisense oligodeoxyribonucleotides against the human epidermal growth factor receptor into cultured $\mathrm{KB}$ cells with liposomes conjugated to folate via polyethylene glycol," Proceedings of the National Academy of 
Sciences of the United States of America, vol. 92, no. 8, pp. 3318-3322, 1995.

[39] H. S. Yoo, J. E. Oh, K. H. Lee, and T. G. Park, "Biodegradable nanoparticles containing doxorubicin-PLGA conjugate for sustained release," Pharmaceutical Research, vol. 16, no. 7, pp. 1114-1118, 1999.

[40] H. S. Yoo and T. G. Park, "Biodegradable polymeric micelles composed of doxorubicin conjugated PLGA-PEG block copolymer," Journal of Controlled Release, vol. 70, no. 1-2, pp. 63-70, 2001.

[41] G. S. Kwon and K. Kataoka, "Block copolymer micelles as long-circulating drug vehicles," Advanced Drug Delivery Reviews, vol. 16, no. 2-3, pp. 295-309, 1995.

[42] G. Kwon, M. Naito, M. Yokoyama, T. Okano, Y. Sakurai, and K. Kataoka, "Block copolymer micelles for drug delivery: loading and release of doxorubicin," Journal of Controlled Release, vol. 48, no. 2-3, pp. 195-201, 1997.

[43] G. Kwon, S. Suwa, M. Yokoyama, T. Okano, Y. Sakurai, and K. Kataoka, "Enhanced tumor accumulation and prolonged circulation times of micelle-forming poly(ethylene oxideaspartate) block copolymer-adriamycin conjugates," Journal of Controlled Release, vol. 29, no. 1-2, pp. 17-23, 1994.

[44] G. S. Kwon, M. Yokoyama, T. Okano, Y. Sakurai, and K. Kataoka, "Biodistribution of micelle-forming polymer-drug conjugates," Pharmaceutical Research, vol. 10, no. 7, pp. 970974, 1993.

[45] Y.-P. Li, Y.-Y. Pei, X.-Y. Zhang et al., "PEGylated PLGA nanoparticles as protein carriers: synthesis, preparation and biodistribution in rats," Journal of Controlled Release, vol. 71, no. 2, pp. 203-211, 2001.

[46] G. F. Joyce, "Amplification, mutation and selection of catalytic RNA," Gene, vol. 82, no. 1, pp. 83-87, 1989.

[47] S. D. Jayasena, "Aptamers: an emerging class of molecules that rival antibodies in diagnostics," Clinical Chemistry, vol. 45, no. 9, pp. 1628-1650, 1999.

[48] S. Tombelli, M. Minunni, E. Luzi, and M. Mascini, "Aptamerbased biosensors for the detection of HIV-1 Tat protein," Bioelectrochemistry, vol. 67, no. 2, pp. 135-141, 2005.

[49] T. Mairal, V. C. Özalp, P. Lozano Sánchez, M. Mir, I. Katakis, and C. K. O'Sullivan, "Aptamers: molecular tools for analytical applications," Analytical and Bioanalytical Chemistry, vol. 390, no. 4, pp. 989-1007, 2008.

[50] R. Nutiu and Y. Li, "Structure-switching signaling aptamers: transducing molecular recognition into fluorescence signaling," Chemistry, vol. 10, no. 8, pp. 1868-1876, 2004.

[51] P. C. Hoffman, A. M. Mauer, and E. E. Vokes, "Lung cancer," Lancet, vol. 355, no. 9202, pp. 479-485, 2000.

[52] J. L. Mulshine and D. C. Sullivan, "Lung cancer screening," New England Journal of Medicine, vol. 352, no. 26, pp. 27142720, 2005.

[53] J. E. Smith, C. D. Medley, Z. Tang, D. Shangguan, C. Lofton, and W. Tan, "Aptamer-conjugated nanoparticles for the collection and detection of multiple cancer cells," Analytical Chemistry, vol. 79, no. 8, pp. 3075-3082, 2007.

[54] X. Zhao, L. R. Hilliard, S. J. Mechery et al., "A rapid bioassay for single bacterial cell quantitation using bioconjugated nanoparticles," Proceedings of the National Academy of Sciences of the United States of America, vol. 101, no. 42, pp. 15027-15032, 2004.

[55] X. Zhao, R. Tapec-Dytioco, and W. Tan, "Ultrasensitive DNA detection using highly fluorescent bioconjugated nanoparticles," Journal of the American Chemical Society, vol. 125, no. 38, pp. 11474-11475, 2003.
[56] X. Zhao, R. P. Bagwe, and W. Tan, "Development of organicdye-doped silica nanoparticles in a reverse microemulsion," Advanced Materials, vol. 16, no. 2, pp. 173-176, 2004.

[57] J. K. Herr, J. E. Smith, C. D. Medley, D. Shangguan, and W. Tan, "Aptamer-conjugated nanoparticles for selective collection and detection of cancer cells," Analytical Chemistry, vol. 78, no. 9, pp. 2918-2924, 2006.

[58] H. W. Chen, C. D. Medley, K. Sefah et al., "Molecular recognition of small-cell lung cancer cells using aptamers," ChemMedChem, vol. 3, no. 6, pp. 991-1001, 2008.

[59] D. J. Javier, N. Nitin, M. Levy, A. Ellington, and R. RichardsKortum, "Aptamer-targeted gold nanoparticles as molecularspecific contrast agents for reflectance imaging," Bioconjugate Chemistry, vol. 19, no. 6, pp. 1309-1312, 2008.

[60] C.-C. Huang, S.-H. Chiu, Y.-F. Huang, and H.-T. Chang, "Aptamer-functionalized gold nanoparticles for turn-on light switch detection of platelet-derived growth factor," Analytical Chemistry, vol. 79, no. 13, pp. 4798-4804, 2007.

[61] O. C. Farokhzad, J. Cheng, B. A. Teply et al., "Targeted nanoparticle-aptamer bioconjugates for cancer chemotherapy in vivo," Proceedings of the National Academy of Sciences of the United States of America, vol. 103, no. 16, pp. 6315-6320, 2006.

[62] O. C. Farokhzad, S. Jon, A. Khademhosseini, T.-N. T. Tran, D. A. LaVan, and R. Langer, "Nanoparticle-aptamer bioconjugates: a new approach for targeting prostate cancer cells," Cancer Research, vol. 64, no. 21, pp. 7668-7672, 2004.

[63] O. C. Farokhzad, A. Khademhosseini, S. Jon et al., "Microfluidic system for studying the interaction of nanoparticles and microparticles with cells," Analytical Chemistry, vol. 77, no. 17, pp. 5453-5459, 2005.

[64] S. Dhar, F. X. Gu, R. Langer, O. C. Farokhza, and S. J. Lippard, "Targeted delivery of cisplatin to prostate cancer cells by aptamer functionalized $\mathrm{Pt}(\mathrm{IV})$ prodrug-PLGAPEG nanoparticles," Proceedings of the National Academy of Sciences of the United States of America, vol. 105, no. 45, pp. 17356-17361, 2008.

[65] Y. Wu, K. Sefah, H. Liu, R. Wang, and W. Tan, "DNA aptamer-micelle as an efficient detection/delivery vehicle toward cancer cells," Proceedings of the National Academy of Sciences of the United States of America, vol. 107, no. 1, pp. 5-10, 2010.

[66] C. Walsh, "Molecular mechanisms that confer antibacterial drug resistance," Nature, vol. 406, no. 6797, pp. 775-781, 2000.

[67] D. Hanahan, G. Bergers, and E. Bergsland, "Less is, more, regularly: metronomic dosing of cytotoxic drugs can target tumor angiogenesis in mice," Journal of Clinical Investigation, vol. 105, no. 8, pp. 1045-1047, 2000.

[68] H. Joensuu, K. Holli, M. Heikkinen et al., "Combination chemotherapy versus single-agent therapy as first- and second-line treatment in metastatic breast cancer: a prospective randomized trial," Journal of Clinical Oncology, vol. 16, no. 12 , pp. 3720-3730, 1998.

[69] Y. Wang, S. Gao, W.-H. Ye, H. S. Yoon, and Y.-Y. Yang, "Co-delivery of drugs and DNA from cationic core-shell nanoparticles self-assembled from a biodegradable copolymer," Nature Materials, vol. 5, no. 10, pp. 791-796, 2006.

[70] Y. Wang, L.-S. Wang, S.-H. Goh, and Y.-Y. Yang, "Synthesis and characterizationo of cationic micelles selfassembled from a biodegradable copolymer for gene delivery," Biomacromolecules, vol. 8, no. 3, pp. 1028-1037, 2007.

[71] N. Wiradharma, Y. W. Tong, and Y.-Y. Yang, "Self-assembled oligopeptide nanostructures for co-delivery of drug and gene 
with synergistic therapeutic effect," Biomaterials, vol. 30, no. 17, pp. 3100-3109, 2009.

[72] L. Cerchia, P. H. Giangrande, J. O. McNamara, and V. de Franciscis, "Cell-specific aptamers for targeted therapies," Methods in Molecular Biology, vol. 535, pp. 59-78, 2009.

[73] T. C. Chu, K. Y. Twu, A. D. Ellington, and M. Levy, "Aptamer mediated siRNA delivery," Nucleic Acids Research, vol. 34, no. 10, article e73, 2006.

[74] J. O. McNamara II, E. R. Andrechek, Y. Wang et al., "Cell type-specific delivery of siRNAs with aptamer-siRNA chimeras," Nature Biotechnology, vol. 24, no. 8, pp. 10051015, 2006.

[75] E. Kim, Y. Jung, H. Choi et al., "Prostate cancer cell death produced by the co-delivery of Bcl-xL shRNA and doxorubicin using an aptamer-conjugated polyplex," Biomaterials, vol. 31, no. 16, pp. 4592-4599, 2010.

[76] Y. Bae, S. Fukushima, A. Harada, and K. Kataoka, "Design of environment-sensitive supramolecular assemblies for intracellular drug delivery: polymeric micelles that are responsive to intracellular $\mathrm{pH}$ change," Angewandte Chemie. International Edition, vol. 42, no. 38, pp. 4640-4643, 2003.

[77] G. Helmlinger, A. Sckell, M. Dellian, N. S. Forbes, and R. K. Jain, "Acid production in glycolysis-impaired tumors provides new insights into tumor metabolism," Clinical Cancer Research, vol. 8, no. 4, pp. 1284-1291, 2002.

[78] Y. Matsumura and H. Maeda, "A new concept for macromolecular therapeutics in cancer chemotherapy: mechanism of tumoritropic accumulation of proteins and the antitumor agent smancs," Cancer Research, vol. 46, no. 12, part 1, pp. 6387-6392, 1986

[79] K. Kataoka, G. S. Kwon, M. Yokoyama, T. Okano, and Y. Sakurai, "Block copolymer micelles as vehicles for drug delivery," Journal of Controlled Release, vol. 24, no. 1-3, pp. 119-132, 1993.

[80] G. S. Kwon and T. Okano, "Polymeric micelles as new drug carriers," Advanced Drug Delivery Reviews, vol. 21, no. 2, pp. 107-116, 1996.

[81] G. S. Kwon, M. Naito, M. Yokoyama, T. Okano, Y. Sakurai, and K. Kataoka, "Physical entrapment of adriamycin in AB block copolymer micelles," Pharmaceutical Research, vol. 12, no. 2, pp. 192-195, 1995.

[82] H. S. Yoo, E. A. Lee, and T. G. Park, "Doxorubicinconjugated biodegradable polymeric micelles having acidcleavable linkages," Journal of Controlled Release, vol. 82, no. 1, pp. 17-27, 2002.

[83] H. S. Yoo, K. H. Lee, J. E. Oh, and T. G. Park, "In vitro and in vivo anti-tumor activities of nanoparticles based on doxorubicin-PLGA conjugates," Journal of Controlled Release, vol. 68, no. 3, pp. 419-431, 2000.

[84] T. M. Allen, "Liposomal drug formulations: rationale for development and what we can expect for the future," Drugs, vol. 56, no. 5, pp. 747-756, 1998.

[85] D. Momekova, S. Rangelov, S. Yanev et al., "Long-circulating, $\mathrm{pH}$-sensitive liposomes sterically stabilized by copolymers bearing short blocks of lipid-mimetic units," European Journal of Pharmaceutical Sciences, vol. 32, no. 4-5, pp. 308317, 2007.

[86] M. C. Woodle, "Sterically stabilized liposome therapeutics," Advanced Drug Delivery Reviews, vol. 16, no. 2-3, pp. 249265, 1995.

[87] S. Zalipsky, "Chemistry of polyethylene glycol conjugates with biologically," Advanced Drug Delivery Reviews, vol. 16, no. 2-3, pp. 157-182, 1995.
[88] A. Gabizon and D. Papahadjopoulos, "Liposome formulations with prolonged circulation time in blood and enhanced uptake by tumors," Proceedings of the National Academy of Sciences of the United States of America, vol. 85, no. 18, pp. 6949-6953, 1988.

[89] M. Hrubý, C. Koňák, and K. Ulbrich, "Polymeric micellar $\mathrm{pH}$-sensitive drug delivery system for doxorubicin," Journal of Controlled Release, vol. 103, no. 1, pp. 137-148, 2005.

[90] M.-S. Hong, S.-J. Lim, Y.-K. Oh, and C.-K. Kim, “pHsensitive, serum-stable and long-circulating liposomes as a new drug delivery system," Journal of Pharmacy and Pharmacology, vol. 54, no. 1, pp. 51-58, 2002.

[91] S. Simões, J. N. Moreira, C. Fonseca, N. Düzgüneş, and M. C. P. de Lima, "On the formulation of $\mathrm{pH}$-sensitive liposomes with long circulation times," Advanced Drug Delivery Reviews, vol. 56, no. 7, pp. 947-965, 2004.

[92] Y. Bae, W.-D. Jang, N. Nishiyama, S. Fukushima, and K. Kataoka, "Multifunctional polymeric micelles with folatemediated cancer cell targeting and $\mathrm{pH}$-triggered drug releasing properties for active intracellular drug delivery," Molecular BioSystems, vol. 1, no. 3, pp. 242-250, 2005.

[93] Y. Bae and K. Kataoka, "Significant enhancement of antitumor activity and bioavailability of intracellular $\mathrm{pH}$-sensitive polymeric micelles by folate conjugation," Journal of Controlled Release, vol. 116, no. 2, pp. e49-e50, 2006.

[94] Y. Bae, N. Nishiyama, S. Fukushima, H. Koyama, M. Yasuhiro, and K. Kataoka, "Preparation and biological characterization of polymeric micelle drug carriers with intracellular $\mathrm{pH}$-triggered drug release property: tumor permeability, controlled subcellular drug distribution, and enhanced in vivo antitumor efficacy," Bioconjugate Chemistry, vol. 16, no. 1, pp. 122-130, 2005.

[95] Y. Bae, N. Nishiyama, and K. Kataoka, "In vivo antitumor activity of the folate-conjugated $\mathrm{pH}$-sensitive polymeric micelle selectively releasing adriamycin in the intracellular acidic compartments," Bioconjugate Chemistry, vol. 18, no. 4, pp. 1131-1139, 2007.

[96] G. Shi, W. Guo, S. M. Stephenson, and R. J. Lee, "Efficient intracellular drug and gene delivery using folate receptor-targeted $\mathrm{pH}$-sensitive liposomes composed of cationic/anionic lipid combinations," Journal of Controlled Release, vol. 80, no. 1-3, pp. 309-319, 2002.

[97] J. J. Sudimack, W. Guo, W. Tjarks, and R. J. Lee, "A novel pH-sensitive liposome formulation containing oleyl alcohol," Biochimica et Biophysica Acta, vol. 1564, no. 1, pp. 31-37, 2002.

[98] T. Ishida, M. J. Kirchmeier, E. H. Moase, S. Zalipsky, and T. M. Allen, "Targeted delivery and triggered release of liposomal doxorubicin enhances cytotoxicity against human B lymphoma cells," Biochimica et Biophysica Acta, vol. 1515, no. 2, pp. 144-158, 2001.

[99] Y. Li and G. S. Kwon, "Methotrexate esters of poly(ethylene oxide)-block-poly(2-hydroxyethyl-L- aspartamide). Part I: effects of the level of methotrexate conjugation on the stability of micelles and on drug release," Pharmaceutical Research, vol. 17, no. 5, pp. 607-611, 2000.

[100] M. G. Rimoli, L. Avallone, P. de Caprariis, A. Galeone, F. Forni, and M. A. Vandelli, "Synthesis and characterisation of poly(D,L-lactic acid)-idoxuridine conjugate," Journal of Controlled Release, vol. 58, no. 1, pp. 61-68, 1999.

[101] M. Zacchigna, G. Di Luca, F. Cateni, S. Zorzet, and V. Maurich, "Improvement of physicochemical and biopharmaceutical properties of theophylline by poly(ethylene glycol) conjugates," Farmaco, vol. 58, no. 12, pp. 1307-1312, 2003. 
[102] K. Hoste, K. de Winne, and E. Schacht, "Polymeric prodrugs," International Journal of Pharmaceutics, vol. 277, no. 1-2, pp. 119-131, 2004.

[103] E. Mastrobattista, G. A. Koning, L. van Bloois, A. C. S. Filipe, W. Jiskoot, and G. Storm, "Functional characterization of an endosome-disruptive peptide and its application in cytosolic delivery of immunoliposome-entrapped proteins," Journal of Biological Chemistry, vol. 277, no. 30, pp. 27135-27143, 2002.

[104] C. J. Provoda, E. M. Stier, and K.-D. Lee, "Tumor cell killing enabled by listeriolysin O-liposome-mediated delivery of the protein toxin gelonin," Journal of Biological Chemistry, vol. 278, no. 37, pp. 35102-35108, 2003.

[105] R. Ishiguro, M. Matsumoto, and S. Takahashi, "Interaction of fusogenic synthetic peptide with phospholipid bilayers: orientation of the peptide $\alpha$-helix and binding isotherm," Biochemistry, vol. 35, no. 15, pp. 4976-4983, 1996.

[106] S. Nir, F. Nicol, and F. C. Szoka Jr., "Surface aggregation and membrane penetration by peptides: relation to pore formation and fusion," Molecular Membrane Biology, vol. 16, no. 1, pp. 95-101, 1999.

[107] J.-C. Leroux, E. Roux, D. Le Garrec, K. Hong, and D. C. Drummond, "N-isopropylacrylamide copolymers for the preparation of $\mathrm{pH}$-sensitive liposomes and polymeric micelles," Journal of Controlled Release, vol. 72, no. 1-3, pp. 71-84, 2001.

[108] T. Mizoue, T. Horibe, K. Maruyama et al., "Targetability and intracellular delivery of anti-BCG antibody-modified, $\mathrm{pH}$-sensitive fusogenic immunoliposomes to tumor cells," International Journal of Pharmaceutics, vol. 237, no. 1-2, pp. 129-137, 2002.

[109] V. P. Torchilin, F. Zhou, and L. Huang, "pH-Sensitive liposomes," Journal of Liposome Research, vol. 3, no. 2, pp. 201-255, 1993.

[110] D. D. Lasic, "Novel applications of liposomes," Trends in Biotechnology, vol. 16, no. 7, pp. 307-321, 1998.

[111] C.-J. Chu, J. Dijkstra, M.-Z. Lai, K. Hong, and F. C. Szoka, "Efficiency of cytoplasmic delivery by $\mathrm{pH}$-sensitive liposomes to cells in culture," Pharmaceutical Research, vol. 7, no. 8, pp. 824-834, 1990.

[112] V. A. Slepushkin, S. Simões, P. Dazin et al., "Sterically stabilized $\mathrm{pH}$-sensitive liposomes. Intracellular delivery of aqueous contents and prolonged circulation in vivo," Journal of Biological Chemistry, vol. 272, no. 4, pp. 2382-2388, 1997.

[113] M. B. Yatvin, J. N. Weinstein, W. H. Dennis, and R. Blumenthal, "Design of liposomes for enhanced local release of drugs by hyperthermia," Science, vol. 202, no. 4374, pp. 1290-1293, 1978.

[114] J. van der Zee, D. González González, G. C. Van Rhoon, J. D. P. Van Dijk, W. L. J. Van Putten, and A. A. M. Hart, "Comparison of radiotherapy alone with radiotherapy plus hyperthermia in locally advanced pelvic tumours: a prospective, randomised, multicentre trial," Lancet, vol. 355, no. 9210, pp. 1119-1125, 2000.

[115] R. D. Issels, L. H. Lindner, P. Wust et al., "Regional hyperthermia (RHT) improves response and survival when combined with systemic chemotherapy in the management of locally advanced, high grade soft tissue sarcomas (STS) of the extremities, the body wall and the abdomen: a phase III randomised prospective trial (EORTC-ESHO intergroup trial)," in Proceedings of the 43rd Annual Meeting of ASCO, Chicago, Ill, USA, 2007.

[116] G. Crile Jr., "Selective destruction of cancers after exposure to heat," Annals of surgery, vol. 156, pp. 404-407, 1962.
[117] G. Kong, R. D. Braun, and M. W. Dewhirst, "Characterization of the effect of hyperthermia on nanoparticle extravasation from tumor vasculature," Cancer Research, vol. 61, no. 7, pp. 3027-3032, 2001.

[118] M. H. Gaber, N. Z. Wu, K. Hong, S. K. Huang, M. W. Dewhirst, and D. Papahadjopoulos, "Thermosensitive liposomes: extravasation and release of contents in tumor microvascular networks," International Journal of Radiation Oncology Biology Physics, vol. 36, no. 5, pp. 1177-1187, 1996.

[119] G. Kong, R. D. Braun, and M. W. Dewhirst, "Hyperthermia enables tumor-specific nanoparticle delivery: effect of particle size," Cancer Research, vol. 60, no. 16, pp. 4440-4445, 2000.

[120] L. Huang, K. Ozato, and R. E. Pagano, "Interactions of phospholipid vesicles with murine lymphocytes. I. Vesiclecell adsorption and fusion as alternate pathways of uptake," Membrane Biochemistry, vol. 1, no. 1-2, pp. 1-25, 1978.

[121] L. F. Fajardo and S. D. Prionas, "Endothelial cells and hyperthermia," International Journal of Hyperthermia, vol. 10, no. 3, pp. 347-353, 1994.

[122] D. Papahadjopoulos, K. Jacobson, S. Nir, and T. Isac, "Phase transitions in phospholipid vesicles. Fluorescence polarization and permeability measurements concerning the effect of temperature and cholesterol," Biochimica et Biophysica Acta, vol. 311, no. 3, pp. 330-348, 1973.

[123] T. Y. Tsong, "Kinetics of the crystalline liquid crystalline phase transition of dimyristoyl L $\alpha$ lecithin bilayers," Proceedings of the National Academy of Sciences of the United States of America, vol. 71, no. 7, pp. 2684-2688, 1974.

[124] T. M. Allen, C. Hansen, F. Martin, C. Redemann, and A. F. Yau-Young, "Liposomes containing synthetic lipid derivatives of poly(ethylene glycol) show prolonged circulation half-lives in vivo," Biochimica et Biophysica Acta, vol. 1066, no. 1, pp. 29-36, 1991.

[125] H. Yoshioka, "Surface modification of haemoglobincontaining liposomes with polyethylene glycol prevents liposome aggregation in blood plasma," Biomaterials, vol. 12, no. 9, pp. 861-864, 1991.

[126] A. R. Nicholas, M. J. Scott, N. I. Kennedy, and M. N. Jones, "Effect of grafted polyethylene glycol (PEG) on the size, encapsulation efficiency and permeability of vesicles," Biochimica et Biophysica Acta, vol. 1463, no. 1, pp. 167-178, 2000.

[127] A. K. Kenworthy, K. Hristova, D. Needham, and T. J. McIntosh, "Range and magnitude of the steric pressure between bilayers containing phospholipids with covalently attached poly(ethylene glycol)," Biophysical Journal, vol. 68, no. 5, pp. 1921-1936, 1995.

[128] S. Mabrey and J. M. Sturtevant, "Investigation of phase transitions of lipids and lipid mixtures by high sensitivity differential scanning calorimetry," Proceedings of the National Academy of Sciences of the United States of America, vol. 73, no. 11, pp. 3862-3866, 1976.

[129] M. Hossann, M. Wiggenhorn, A. Schwerdt et al., "In vitro stability and content release properties of phosphatidylglyceroglycerol containing thermosensitive liposomes," Biochimica et Biophysica Acta, vol. 1768, no. 10, pp. 2491-2499, 2007.

[130] D. Needham, G. Anyarambhatla, G. Kong, and M. W. Dewhirst, "A new temperature-sensitive liposome for use with mild hyperthermia: characterization and testing in a human tumor xenograft model," Cancer Research, vol. 60, no. 5, pp. 1197-1201, 2000.

[131] L. H. Lindner, M. E. Eichhorn, H. Eibl et al., "Novel temperature-sensitive liposomes with prolonged circulation 
time," Clinical Cancer Research, vol. 10, no. 6, pp. 2168-2178, 2004.

[132] G. Kong, G. Anyarambhatla, W. P. Petros et al., "Efficacy of liposomes and hyperthermia in a human tumor xenograft model: importance of triggered drug release," Cancer Research, vol. 60, no. 24, pp. 6950-6957, 2000.

[133] M. L. Hauck, S. M. La Rue, W. P. Petros et al., "Phase I trial of doxorubicin-containing low temperature sensitive liposomes in spontaneous canine tumors," Clinical Cancer Research, vol. 12, no. 13, pp. 4004-4010, 2006.

[134] O. Soga, C. F. van Nostrum, A. Ramzi et al., "Physicochemical characterization of degradable thermosensitive polymeric micelles," Langmuir, vol. 20, no. 21, pp. 9388-9395, 2004.

[135] D. Neradovic, C. F. van Nostrum, and W. E. Hennink, "Thermoresponsive polymeric micelles with controlled instability based on hydrolytically sensitive $\mathrm{N}$-isopropylacrylamide copolymers," Macromolecules, vol. 34, no. 22, pp. 7589-7591, 2001.

[136] O. Soga, C. F. van Nostrum, and W. E. Hennink, "Poly(N(2-hydroxypropyl) methacrylamide mono/di lactate): a new class of biodegradable polymers with tuneable thermosensitivity," Biomacromolecules, vol. 5, no. 3, pp. 818-821, 2004.

[137] C. J. F. Rijcken, T. F. J. Veldhuis, A. Ramzi, J. D. Meeldijk, C. van Nostrum, and W. E. Hennink, "Novel fast degradable thermosensitive polymeric micelles based on PEG-blockpoly(N-(2-hydroxyethyl)methacrylamide-oligolactates)," Biomacromolecules, vol. 6, no. 4, pp. 2343-2351, 2005.

[138] G. Molineux, "Pegylation: engineering improved pharmaceuticals for enhanced therapy," Cancer Treatment Reviews, vol. 28, supplement A, pp. 13-16, 2002.

[139] O. Soga, C. F. van Nostrum, M. Fens et al., "Thermosensitive and biodegradable polymeric micelles for paclitaxel delivery," Journal of Controlled Release, vol. 103, no. 2, pp. 341-353, 2005.

[140] O. Soga, In vivo efficacy of paclitaxel-loaded thermosensitive biodegradable polymeric micelles, M.S. thesis, Department of Pharmaceutics, Utrecht Institute for Pharmaceutical Sciences, Utrecht, The Netherlands, 2006.

[141] C. J. Rijcken, C. J. Snel, R. M. Schiffelers, C. F. van Nostrum, and W. E. Hennink, "Hydrolysable core-crosslinked thermosensitive polymeric micelles: synthesis, characterisation and in vivo studies," Biomaterials, vol. 28, no. 36, pp. 5581$5593,2007$. 

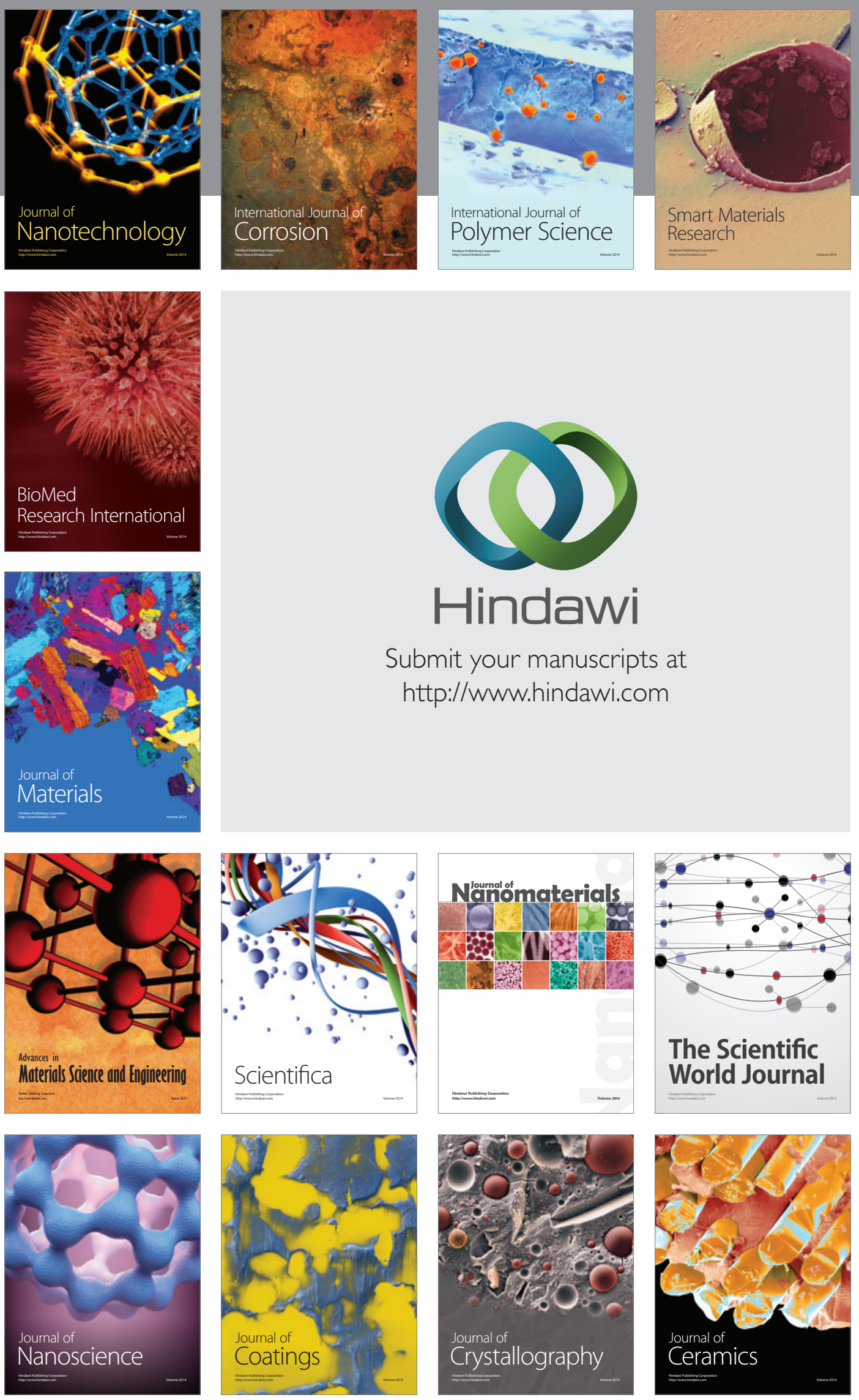

The Scientific World Journal

Submit your manuscripts at

http://www.hindawi.com

\section{World Journal}

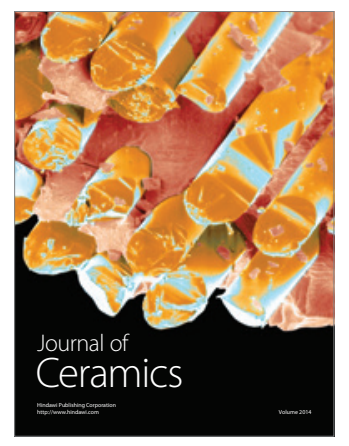

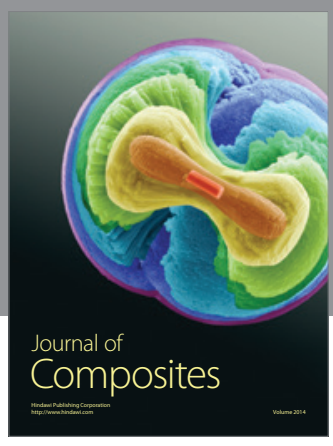
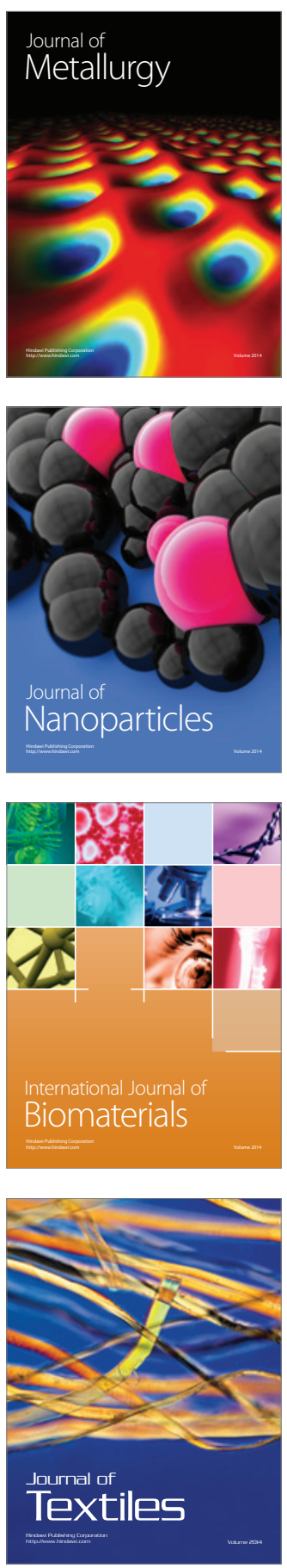